\title{
The April $2017 M_{w} 6.5$ Botswana Earthquake: An Intraplate Event Triggered by Deep Fluids
}

\author{
B. Gardonio, R. Jolivet, E. Calais \& H. Leclère \\ Laboratoire de Géologie, Département de Géosciences, École Normale Supérieure, \\ CNRS UMR 8538, PSL Research University, 75005 Paris, France
}

\begin{abstract}
Key Points:
- Our InSAR-based estimate of the source parameters indicates a deep event with two probable families of models.

- We detect a precursory phase using template matching at teleseismic distances to the mainshock.

- A transient pulse of fluids is likely required to trigger this event, maybe a common stress perturbation at the origin of intraplate events
\end{abstract}

This is the accepted version of the manuscript. There might be minor differences with the published article following editing, proof-reading and publication 


\begin{abstract}
Large earthquakes in Stable Continental Regions (SCR) remain puzzling as, unlike at plate boundaries, they do not result from the local build-up of strain driven by plate tectonics. The 2017, $\mathrm{M}_{\mathrm{w}} 6.5$, Bostwana normal-faulting earthquake occurred in a region devoid from recent tectonic activity and where present-day deformation is negligible. The depth of the event $(29 \pm 4 \mathrm{~km})$, in a felsic lower crust where ductile deformation is expected, likely requires a transient pulse of fluids from a deep source to activate brittle faulting. The mainshock was preceded by two foreshock swarm-like sequences that may be further evidence for fluid movement in a critically loaded fault network. Contrary to plate boundary events, the $M_{w} 6.5$ Botswana earthquake did not require prior localized stress or strain accumulation. We propose that the crust in SCR, even long after the last tectonic episode, constitutes a reservoir of elastic stress that can be released episodically, for instance as a result of deep fluid migration.
\end{abstract}


While earthquakes primarily occur along plate boundaries, where most of the tectonic strain is released, large events also strike stable continental interiors, although much less frequently [e.g. Johnston, 1989; Calais et al., 2016]. The New Madrid region of the Central U.S., with four M>7 events between December 1811 and February 1812, is a type locale for large earthquakes in such settings [e.g. Nuttli, 1973; Johnston, 1996; Hough et al., 2000], and examples can be found in all continents. South Africa was struck in 1969 by the $\mathrm{M}_{\mathrm{w}} 6.3$ Ceres earthquake [Kruger and Scherbaum, 2014], and in 1998, the Tennant Creek sequence of $\mathrm{M}_{\mathrm{s}}$ 6.3, 6.4, and 6.7 events shook central Australia [Bowman, 1992]. Careful studies of such rare events are important as the mechanism leading to stress release on faults in regions of very low tectonic deformation remains poorly understood, leading to large uncertainties in hazard assessment in populated continental interiors [e.g. Allman and Smolka, 2001; Liu and Stein, 2016]. We focus on the largest stable continental interior earthquake since the 1998 Tennant Creek events, a $\mathrm{M}_{\mathrm{w}} 6.5$ normal-faulting earthquake that ruptured a blind fault in Botswana on April 3rd, 2017, within the Kalahari cratonic domain, far from any identified active fault (Fig. 1).

The $\mathrm{M}_{\mathrm{w}} 6.5$ Bostwana earthquake occurred close to the junction between the Archean Kaapval craton and the Paleoproterozoic Mahalapye granite of the Limpopo belt (Fig. 1). It may have reactivated one of the high angle faults that mark the boundary between these old and seismically quiet geological units [Kolawole et al., 2017]. Seismic activity in its epicentral region $\left(-25^{\circ}\right.$ to $-21^{\circ}$ south, $23^{\circ}$ to $27^{\circ}$ east $)$ is more elevated than typical stable continental interiors, with 23 earthquakes of magnitude larger than 4 detected since January 1st, 2000. The mainshock was followed by about 30 aftershocks of magnitude greater than 3, as reported by the International Seismological Center (ISC). Aftershocks appear to first extend over a large region before focusing closer to the epicenter, though this may be biased by the location capability of small events at teleseismic distances. One of the objectives of this study is to expand this aftershock catalog and, more importantly, to search for potential foreshocks, using for the first time a template matching technique at teleseismic distances from the mainshock.

Although southern Africa experiences diffuse, low magnitude seismicity [e.g. Pastier et al., 2017], no active structure has been identified in the epicentral region of the Botswana earthquake. The nearest active faults are $350 \mathrm{~km}$ to the north bounding the isolated Okavango tectonic basin, where a M6.7 earthquake occurred in 1952 [Modisi et al., 2000; Reeves, 1972]. This basin has been interpreted by some as an incipient rift at the western 
end of a belt of weak seismicity that extends from the Okavango basin through the Kariba graben to the east and connects to the Rukwa region of the East African Rift [Scholz et al., 1976; Modisi et al., 2000], although that interpretation has recently been challenged [Pastier et al., 2017]. The 2017 Bostwana earthquake is located well away from these structures. Its GCMT mechanism and fault plane solutions derived from Differential InSAR data show a fault plane striking perpendicular to this possible direction of rift propagation [Kolawole et al., 2017; Albano et al., 2017]. However, these published InSARderived fault models did not explore the whole range of possible fault planes and another objective of this study is to re-evaluate the source mechanism and depth of this earthquake.

In the following, we show that the Bostwana earthquake (1) occurred at a depth of $29 \mathrm{~km}$, in the lower crust, on a $73^{\circ}$ or a $17^{\circ}$-dipping fault, and (2) was preceded by two foreshock sequences. We argue that this earthquake sequence was triggered by a local and transient pulse of elevated pore fluid pressure in a lower crust where viscous deformation should otherwise prevail.

\section{InSAR analysis and Bayesian source parameters estimation}

We compute an interferogram from Sentinel-1 acquisitions in interferometric wideswath mode on March 30th and April 11th 2017 along ascending orbits (see Supp. Mat.). We identify surface displacements resulting from this normal faulting event as the ovalshaped set of fringes located in the epicentral region (Fig. 2). We measure about $4 \mathrm{~cm}$ of coseismic surface displacement in the satellite Line-Of-Sight (LOS). Given the incidence angle of the Radar signal in the epicentral region and assuming negligible horizontal motion, this corresponds to about $6 \mathrm{~cm}$ of subsidence.

We use a Bayesian formulation to invert for the source parameters of the mainshock. The goal is to find wether it is possible to discriminate between the 2 possible fault planes provided by the GCMT solution. We select a subset of the interferogram and downsample the interferometric phase using a curvature-based quadtree algorithm [Fig 2 and Supp. Mat. Fig. S1; Simons et al., 2002]. Our model set up includes a single fault plane with constant slip embedded in an elastic homogeneous medium. We solve for the fault centroid position (longitude, latitude and depth), its orientation (strike and dip), and the amount of slip along dip. We consider its size fixed (10 km along dip and 
$30 \mathrm{~km}$ along strike, chosen based on orders of magnitude for $\mathrm{M}_{\mathrm{w}} 6$ earthquakes) as these size parameters trade-off with slip. In addition, we solve for a constant offset to add to the InSAR data.

Following Bayes' theorem, we write the posterior Probability Density Function (PDF) of the model, $P(\mathbf{m} \mid \mathbf{d})$, as proportional to the product of the prior PDF, $P(\mathbf{m})$, and the likelihood, $P(\mathbf{d} \mid \mathbf{m})$,such as

$$
P(\mathbf{m} \mid \mathbf{d}) \propto P(\mathbf{m}) P(\mathbf{d} \mid \mathbf{m})
$$

where $\mathbf{m}$ is the vector of model parameters and $\mathbf{d}$ the vector of data to invert (i.e. here, the downsampled surface displacements from InSAR). We use uniform distributions for the prior PDF, imposing positivity on slip (i.e., the fault has to be a normal fault). We use a Gaussian formulation for the likelihood, $P(\mathbf{d} \mid \mathbf{m})$, that writes

$$
P(\mathbf{d} \mid \mathbf{m}) \propto e^{-\frac{1}{2}(\mathbf{G m}-\mathbf{d})^{T} \mathbf{C}_{\mathrm{d}}^{-1}(\mathbf{G m}-\mathbf{d})}
$$

where, $\mathbf{G}$ is the matrix of Green's functions relating source parameters to surface displacements and $\mathbf{C}_{\mathrm{d}}$ is the data covariance matrix. We build the Green's functions using Okada's formulation of the surface displacements produced by slip on a rectangular dislocation [OKada, 1985]. We use the covariance function of the interferogram to build the data covariance matrix, describing the influence of turbulent tropospheric noise [see Supp. Mat.; Jolivet et al., 2015].

In the present case, the posterior PDF must be multimodal as both southwest- and northeast-dipping fault planes should be able to fit surface displacements. Using a classic sampling approach, for instance based on the long-used Metropolis algorithm, will unlikely resolve directly the complete shape of the PDF as the probability for one Markov chain to jump between isolated, high probability regions of the model space is very low. This is likely why a previously published Bayesian model does not show multiple modes for the posterior PDF, hence multiple possible dip angles [Albano et al., 2017]. Even if this probability is not null and sampling all regions of the model space should theoretically be possible with a classic Metropolis algorithm [Xu et al., 2015], a prohibitive number of steps would be required. Furthermore, it would be difficult to assert the respec- 
tive importance of each mode. We use instead the AlTar sampler, specifically designed for high dimensional problems and complex PDF sampling (see Supp. Mat.).

Our posterior PDF shows four family of models, including two equally likely and two equally less likely that we separate using a K-mean clustering algorithm (Supp. Fig. S3). The two most likely families of models have an average depth of $29 \pm 4 \mathrm{~km}$, an average magnitude of $6.54 \pm 0.05$ and their centroid location is consistent with that from GCMT. Members from these 2 families only differ by their dip angle, one being on average $17^{\circ} \pm 4^{\circ}$ and the other at $73^{\circ} \pm 4^{\circ}$, hence the two possible families of strike angle at $180^{\circ}$ from eachother. These values are similar to those of the conjugate planes of the GCMT solution, with slightly steeper or shallower dip angles for the steep - and a shallow - angle planes, respectively. The InSAR derived centroid location and magnitude are consistent within uncertainties with those determined by GCMT. We will not further consider the less likely families as their fault strike and magnitude, centroid location, and depth are not consistent with the seismologically-derived ones. Finally, our results indicate that it is not possible to discriminate between a steep and a shallow angle normal faulting event as both families of models are equiprobable.

\section{Aftershocks and foreshocks detection}

We then seek to detect aftershocks and possible foreshocks of the Botswana earthquake. Since no data from local seismic networks were available at the time of this work, we apply template matching to continuous signals recorded at teleseismic distances (1200 to $2000 \mathrm{~km}$ ) to the mainshock from November 2016 to April 2017. This technique has been used to detect low frequency earthquakes (LFE) within tremor signals [Shelly et al., 2007] or to recover missing events in aftershock [Lengliné and Marsan, 2009; Peng and Zhao, 2009] and foreshock sequences [Bouchon et al., 2011; Kato et al., 2012; Lengliné et al., 2012; Kato and Nakagawa, 2014; Gardonio, 2017]. It is however more challenging at teleseismic distances because of the much lower signal-to-noise ratio of the seismic records compared to near-field observations.

We select as templates $18 \mathrm{M}>3$ aftershocks that occurred in the week following the main event to compute their coherence with continuous seismic records at five teleseismic stations (Fig. 1). We obtain a continuous record of the coherence per template and per day. We define a coherence threshold above which we consider that an event has been de- 
tected (see Supp. Mat.). Figure 3 shows the cumulative number of events detected at least at 2 teleseismic stations using coherence thresholds of $0.89,0.9$, and 0.91 after removing auto-detections, i.e. detections of a template by itself. As expected, the number of detections increases with decreasing threshold. All events are seismic in origin but some of the lower-threshold ones are located up to $35 \mathrm{~km}$ away from the mainshock epicenter, suggesting a fairly broad seismically active region both before and after the mainshock. We also observe, for all detection thresholds, an increase in seismicity between December 4th and 30th, 2016 - four months before the main event - while only one M4.1 earthquake was reported by the ISC within $120 \mathrm{~km}$ of the main shock during that same time interval.

At the 0.91 coherence threshold, we detect a total of 20 new events (see Supp. Mat.). We manually checked these detections for each station. This number is expectedly much smaller than near-field template matching studies [Kato et al., 2012; Lengliné et al., 2012; Kato and Nakagawa, 2014] but nevertheless shows a remarkable temporal distribution, with two sequences of foreshocks. The first one occurs between 4 and 3 months before the mainshock, with 9 events detected by templates south-west of the mainshock epicenter (Supp. Mat. Fig. S4). Its is followed by a seismically quiet time interval until early March. The second foreshock sequence occurs during the 2 weeks that precede the main event, with 5 events detected by three templates north-west of the mainshock.

\section{A precursory geodetic signal?}

By reference to other preparatory phases identified before large earthquakes, the foreshocks detected here may be embedded in a broader aseismic event [Ruiz et al., 2014; Bouchon et al., 2011]. In order to detect such an event, we processed all available Sentinel1 acquisitions between April 2015 and August 2017 (Supp. Mat.). The resulting time series of relative surface displacements between the epicentral region $(<10 \mathrm{~km}$ from the epicenter) and the far-field (> $60 \mathrm{~km}$ from the epicenter) shows no significant signal within the precursory phase during which small earthquakes are detected (Fig. 3). The same holds for the full time series (Supp. Fig. S8 to S11). The coseismic signal is well recovered, with a $2-3 \mathrm{~cm}$ offset at the time of the main shock. Averaging over the last 11 acquisitions of the time series suggests that the coseismic offset is followed by up to $1 \mathrm{~cm}$ of post-seismic displacements. 


\section{Present-day regional strain accumulation?}

The location of the Bostwana earthquake far from areas of concentrated seismic activity, in a region with no morphological evidence of recent tectonic activity, raises the question of present-day strain accumulation in southern Africa. The low strain rates expected in such an intraplate setting may be difficult to measure geodetically, especially since the distribution of GPS stations is sparse and uneven. Nevertheless, it is useful to try place an upper-bound on regional strain accumulation using the existing permanent GPS stations. We therefore updated the analysis of data from openly available, continuouslyrecording GPS stations in southern Africa to derive a continental-scale velocity field in order to search for region-wide deformation (Supp. Mat. and Fig. 1).

We search for deviations from a purely rigid behavior by estimating a single rigid rotation for the whole region considered here and examining residual velocities. We find no spatial pattern in residual velocities with respect to a rigid plate (Fig. 1) with an RMS misfit of $0.25 \mathrm{~mm} / \mathrm{yr}$ (maximum residual of $0.95 \mathrm{~mm} / \mathrm{yr}$ ), and a $\chi^{2}$ of 1.1. The comparison of the distribution of residual velocities, normalized by their uncertainty, with that of a two-dimensional, unit variance, normal distribution shows that the velocities are well described by a random process (Fig. 1). Although the uneven geographic distribution of GPS stations in southern Africa is not optimal for this type of study, our results rule out the possibility of broad-scale deformation at a level of $0.25 \mathrm{~mm} / \mathrm{yr}$, consistent with observations in several other plate interiors [Nocquet, 2012; Tregoning et al., 2013; Craig and Calais, 2014], as well as previous results in the same region [Hackl et al., 2011; Saria et al., 2014].

\section{What caused the Botswana earthquake?}

The 2017, $\mathrm{M}_{\mathrm{w}} 6.5$, Botswana earthquake occurred in an area with no previous evidence of similar magnitude events, low and diffuse background seismicity, and no topographic features indicative of repeated recent faulting, characteristics that are shared by most large earthquakes in stable continental regions [Calais et al., 2016]. That the earthquake focal mechanism shows purely normal faulting is consistent with the occurrence of other normal faulting earthquakes within stable southern Africa [Heidbach et al., 2016] and with stress models derived from horizontal gradients of gravitational potential energy [Coblentz and Sandiford, 1994; Stamps et al., 2014]. Both indicate an extensional stress 
state with a subvertical maximum principal compressive stress $\left(\sigma_{1}\right)$ and a subhorizontal least principal compressive stress $\left(\sigma_{3}\right)$.

However, a striking feature of the event is its depth, which all authors consistently find between 25 and $30 \mathrm{~km}$, well into the lower part of a crust that is around $35 \mathrm{~km}$-thick in the epicentral area [Nguuri et al., 2001; Tedla et al., 2011; Youssof et al., 2013]. The occurence of earthquakes in the lower crust is often interpreted as evidence for a mafic composition [Shudofsky et al., 1987; Nyblade and Langston, 1995; Albaric et al., 2008; Craig et al., 2011]. Seismic data in the Kaapval craton however show a low Poisson ratio of 0.25 for the whole crust and a $2,860 \mathrm{~kg} / \mathrm{m}^{3}$ lowermost crust density, indicative of a felsic composition [James et al., 2003], consistent with the lack of mafic granulite xenoliths from the lower Kaapvaal crust [Schmitz and Bowring, 2003].

Given a crustal geotherm derived from local surface heat flow measurements, crustal yield strength enveloppes for the region (Fig. 4a) show that brittle failure should not happen at such depth, under hydrostatic pore-fluid pressure, as a felsic lower crust flows at low differential stress. In the absence of a mafic lower crust, (1) the maximum differential stress that can be maintained at hypocentral depth is about 50-100 MPa and (2) deformation at such depth is controlled by viscous flow. However, if pore-fluid pressure becomes sub-lithostatic, brittle failure on a $73^{\circ}$-dip fault is allowed at a differential stress lower than $50 \mathrm{MPa}$ (Fig. 4c). Alternate mechanisms are also possible, such as thermal shear runaway, rupture of a brittle asperity, or dehydration reactions [e.g. Green and Houston, 1995; Prieto et al., 2013]. The former two require significant, on-going, shear motion, which is unlikely in this stable cratonic environment. The latter implies a phase transition, which would require a recent rejuvenation of the cratonic crust that is not documented. The stability of the cratonic crust requires an external forcing to trigger this event.

Therefore, a likely explanation for the Botswana earthquake is that it was triggered by elevated, sub-lithostatic, pore fluid pressure that enabled failure at the low differential stress that prevails in the viscous lower crust [Gold and Soter, 1985]. The observed foreshock swarm-like sequences may be the signature of the initiation of a pulse of high pore fluid pressure [Hainzl and Fischer, 2002; Reyners et al., 2007; Balfour et al., 2015]. Field observations show numerous evidence of fluid-assisted embrittlement in the viscous regime of deformation [Handy et al., 2007; Wehrens et al., 2016]. Lower-crustal earthquakes in the northern Alpine foreland [Deichmann, 1992] and beneath the Flinders 
Ranges of South Australia [Balfour et al., 2015] have been interpreted as the result of a decrease of effective stress on pre-existing faults by fluids at near-lithostatic pore pressure, allowing a switch from viscous to brittle deformation. In the later case, the authors argued for a deep fluid source from a remnant hydrated mantle on the basis of elevated ${ }^{3} \mathrm{He} /{ }^{4} \mathrm{He}$ ratios in springs, as also observed in Vogtland, Bohemia, and Eger Rift intraplate seismicity areas of Central Europe [Weise et al., 2001; Bräuer et al., 2009]. In the Taupo active rift (New Zealand), lower-crustal earthquakes in the viscous regime are interpreted as triggered by fluids migrating upward from the hydrated Hikurangi subduction mantle wedge [Reyners et al., 2007].

Southern Africa is a largely cratonic province characterized by widespread kimberlite outcrops, which take their source in carbonate-rich matrices and parental magma [Kamenetsky et al., 2014]. Rapid kimberlite melt ascent through the crust is assumed to be driven by the exsolution of a $\mathrm{H}_{2} \mathrm{O}$ - and $\mathrm{CO}_{2}$-rich fluid phases at mantle depths [Russell et al., 2012]. This requires the presence of volatiles in the mantle, which can be hosted in the lower lithosphere until remobilization under large-scale tensional tectonic stresses as shown in the Virunga volcanic field of the East African Rift [Hudgins et al., 2015]. In the Okavango basin, $350 \mathrm{~km}$ north of the Botswana earthquake, a thermal anomaly measured in the absence of surface magmatism and of a thinned or altered lithosphere is interpreted as the signature of fluids advected from a metasomatized lithospheric mantle [Leseane et al., 2015]. Therefore, several lines of evidence point to the presence of significant amounts of fluids in the upper mantle underneath southern and eastern Africa. The upward migration of these deep and buoyant fluids could perhaps explain the locally elevated pore-fluid pressure necessary to trigger seismicity in the otherwise ductile lower crust of the Kaapval craton.

\section{Conclusion}

The occurrence of the April 3rd, 2017, Botswana earthquake in a felsic lower crust where viscous deformation should prevail indicates that pore-fluid pressure elevated to sub-lithostatic played a key role in triggering the rupture. The two swarm-like sequences of earthquakes that preceded the main Botswana event in December and March 2017 may be further evidence for fluid movement in a critically loaded fault network, that eventually led to a large event. Finally, the damage caused by the mainshock potentially led to a de- 
crease in pore-fluid pressure locally, turning off the activity of this swarm-like sequence, hence the detection of a classic Omori decay of aftershock productivity.

The Botswana earthquake therefore did not require localized, present-day, stress or strain accumulation, contrary to plate boundary events resulting from the near-fault accrual of stress imposed by plate and block motions [Kanamori and Brodsky, 2004]. In a pre-stressed crust able to store reversible strain on long timescales [Feldl and Bilham, 2006; Craig et al., 2016] with faults at or close to failure [Townend and Zoback, 2000], short-term fault strength transients, such as those triggered by fluids leaks from the upper mantle, may be all it takes to trigger large events.

\section{Acknowledgments}

We thank IRIS for granting access to seismic data (http://ds.iris.edu/SeismiQuery). Sentinel $1 \mathrm{~A}$ and $\mathrm{B}$ acquisitions were downloaded through the Plateforme d'Exploitation des Produits Sentinel (PEPS, https://peps.cnes.fr) of the Centre National des Études Spatiales (CNES). The seismic catalog was downloaded through the ISC website (http://www.isc.ac.uk/). Global Precipitation Measurement data are available for download at https://pmm.nasa.gov/GPM. BG received funding from the European Research Council (ERC) under the European Union's Horizon 2020 research and innovation program (REALISM project, grant agreement 681346). RJ received funding from the European Research Council (ERC) under the European Union's Horizon 2020 research and innovation program (Geo-4D project, grant agreement 758210). EC acknowledges support from the Institut Universitaire de France and from the INSU/CNRS Tellus-Rift program. We thank K. Materna and an anonymous reviewer for the time they took at evaluating our work and their constructive comments.

\section{References}

Albano, M., M. Polcari, C. Bignami, M. Moro, M. Saroli, and S. Stramondo (2017), Did anthropogenic activities trigger the 3 april 2017 mw 6.5 botswana earthquake?, Rem. Sens., 9(12), doi:10.3390/rs9101028.

Albaric, J., J. Déverchère, C. Petit, J. Perrot, and B. Le Gall (2008), Crustal rheology and depth distribution of earthquakes: Insights from the central and southern East African Rift System, Tecton., 468(1-4), 28-41.

Allman, A., and A. Smolka (2001), Increasing Loss Potential in Earthquake Risk-A Reinsurance Perspective, in Proceedings of the Workshop: Evaluation of the potential for large 
earthquakes in regions of present-day low seismic activity in Europe, edited by T. Camelbeeck, pp. 1-4.

Balfour, N. J., P. R. Cummins, S. Pilia, and D. Love (2015), Localization of intraplate deformation through fluid-assisted faulting in the lower-crust: The Flinders Ranges, South Australia, Tecton., 655(C), 97-106, doi:10.1016/j.tecto.2015.05.014.

Ballard, S., H. N. Pollack, and N. J. Skinner (1987), Terrestrial heat flow in Botswana and Namibia, J. Geophys. Res., 92(B7), 6291-6300.

Bouchon, M., H. Karabulut, M. Aktar, S. Ozalaybey, J. Schmittbuhl, and M. Bouin (2011), Extended nucleation of the $1999 \mathrm{Mw}$ 7.6 Izmit earthquake, Science, 331, doi:10.1126/ science.1197341.

Bowman, J. R. (1992), The 1988 Tennant Creek, northern territory, earthquakes: A synthesis, Aust. J. Earth Sci, 39(5), 651-669.

Bräuer, K., H. Kämpf, and G. Strauch (2009), Earthquake swarms in non-volcanic regions: What fluids have to say, Geophys. Res. Lett., 36(17), 481-5, doi:10.1029/ 2009GL039615.

Byerlee, J. (1978), Friction of rocks, Pure Appl. Geophys., 116(4-5), 615-626.

Calais, E., T. Camelbeeck, S. Stein, M. Liu, and T. J. Craig (2016), A new paradigm for large earthquakes in stable continental plate interiors, Geophys. Res. Lett., 43(20), 10,621-10,637, doi:10.1002/2016GL070815.

Coblentz, D. D., and M. Sandiford (1994), Tectonic stresses in the African plate: Constraints on the ambient lithospheric stress state, Geology, 22(9), 831-834.

Craig, T. J., and E. Calais (2014), Strain accumulation in the New Madrid and Wabash Valley seismic zones from 14 years of continuous gps observation, J. Geophys. Res. Solid Earth, 119, 9110-9129, doi:10.1002/2014JB011498.

Craig, T. J., J. A. Jackson, K. Priestley, and D. McKenzie (2011), Earthquake distribution patterns in Africa: their relationship to variations in lithospheric and geological structure, and their rheological implications, Geophys. J. Int., 185(1), 403-434.

Craig, T. J., E. Calais, L. Fleitout, L. Bollinger, and O. Scotti (2016), Evidence for the release of long-term tectonic strain stored in continental interiors through intraplate earthquakes, Geophys. Res. Lett., 43, 6826-6836, doi:10.1002/2016GL069359.

Deichmann, N. (1992), Structural and rheological implications of lower-crustal earthquakes below northern Switzerland, Phys. Earth Planet. Inter, 69, 270-280. 
Ekström, G., M. Nettles, and A. M. Dziewonski (2012), The global CMT project 20042010: Centroid-moment tensors for 13,017 earthquakes, Phys. Earth Planet. Inter., pp. 200-201, doi:10.1016/j.pepi.2012.04.002.

Farr, T. G., and M. Kobrick (2000), Shuttle radar topography mission produces a wealth of data, Eos Trans. AGU, 81(48), 583-585.

Feldl, N., and R. Bilham (2006), Great Himalayan earthquakes and the Tibetan plateau, Nature, 444(7116), 165-170, doi:10.1038/nature05199.

Gardonio, B. (2017), Seismic and aseismic slip: the japanese subduction zone, Ph.D. thesis, Université Savoie Mont Blanc.

Gold, T., and S. Soter (1985), Fluid ascent through the solid lithosphere and its relation to earthquakes, Pure Appl. Geophys., 122(2-4), 492-530.

Green, H. W., and H. Houston (1995), The Mechanics of Deep Earthquakes, Ann. Rev. Earth Planet. Sci., 23(1), 169-213, doi:10.1146/annurev.ea.23.050195.001125.

Hackl, M., R. Malservisi, U. Hugentobler, and R. Wonnacott (2011), Estimation of velocity uncertainties from GPS time series: Examples from the analysis of the South African TrigNet network, J. Geophys. Res, 116(B11), B11,404-12.

Hainzl, S., and T. Fischer (2002), Indications for a successively triggered rupture growth underlying the 2000 earthquake swarm in Vogtland/NW Bohemia, J. Geophys. Res. Solid Earth, 107(B12), ESE 5-1-ESE 5-9.

Handy, M., G. Hirth, and R. Burgmann (2007), Continental fault structure and rheology from the frictional-to-viscous transition downward, In: Handy, M.R., Hirth, G., Hovius, N. (Eds.), Tectonic Faults: Agents of Change on a Dynamic Earth. MIT, Cambridge, MA, pp. 139-181.

Heidbach, O., M. Rajabi, K. Reiter, M. Ziegler, and W. Team (2016), World stress map database release 2016, GFZ Data Services, doi:http://doi.org/10.5880/WSM.2016.001.

Hirth, G., C. Teyssier, and J. W. Dunlap (2001), An evaluation of quartzite flow laws based on comparisons between experimentally and naturally deformed rocks, International Journal of Earth Sciences, 90(1), 77-87.

Hough, S. E., J. G. Armbruster, L. Seeber, and J. F. Hough (2000), On the Modified Mercalli intensities and magnitudes of the 1811-1812 New Madrid earthquakes, J. Geophys. Res Solid Earth, 105(B10), 23,839-23,864.

Hudgins, T. R., S. B. Mukasa, A. C. Simon, G. Moore, and E. Barifaijo (2015), Melt inclusion evidence for $\mathrm{CO} 2$-rich melts beneath the western branch of the East African 
Rift: implications for long-term storage of volatiles in the deep lithospheric mantle, Contributions to Mineralogy and Petrology, 169, 1-18.

James, D. E., F. Niu, and J. R. Lithos (2003), Crustal structure of the Kaapvaal craton and its significance for early crustal evolution, Lithos, 71, 413-429.

Johnston, A. C. (1989), The Seismicity of 'Stable Continental Interiors', in Earthquakes at North-Atlantic Passive Margins: Neotectonics and Postglacial Rebound, pp. 299-327, Springer Netherlands, Dordrecht.

Johnston, A. C. (1996), Seismic moment assessment of earthquakes in stable continental regions-II. Historical seismicity, Geophys. J. Int, 125, 639-678.

Jolivet, R., M. Simons, P. S. Agram, Z. Duputel, and Z.-K. Shen (2015), Aseismic slip and seismogenic coupling along the central San Andreas Fault, Geophys. Res. Lett., 42(2), 297-306, doi:10.1002/2014GL062222.

Kamenetsky, V. S., A. V. Golovin, R. Maas, A. Giuliani, M. B. Kamenetsky, and Y. Weiss (2014), Towards a new model for kimberlite petrogenesis: Evidence from unaltered kimberlites and mantle minerals, Earth Science Reviews, 139(C), 145-167.

Kanamori, H., and E. E. Brodsky (2004), The physics of earthquakes, Rep. Prog. Phys., 67(8), 1429-1496, doi:10.1088/0034-4885/67/8/R03.

Kato, A., and S. Nakagawa (2014), Multiple slow-slip events during a foreshock sequence of the 2014 Iquique, Chile Mw 8.1 earthquake, Geophys. Res. Lett., 41(15), 5420-5427, doi:10.1002/2014GL061138.

Kato, A., K. Obara, T. Igarashi, H. Tsuruoka, S. Nakagawa, and N. Hirata (2012), Propagation of slow slip leading up to the $2011 \mathrm{Mw} 9.0$ Tohoku-Oki earthquake, Science, 335, 705-708, doi:10.1126/science.1215141.

Kolawole, F., E. A. Atekwana, S. Malloy, D. S. Stamps, R. Grandin, M. G. Abdelsalam, K. Leseane, and E. M. Shemang (2017), Aeromagnetic, gravity, and Differential Interferometric Synthetic Aperture Radar analyses reveal the causative fault of the 3 april 2017 Mw6.5 Moiyabana, Botswana, earthquake, Geophys. Res. Lett., 44(17), 8837-8846, doi:10.1002/2017GL074620.

Kruger, F., and F. Scherbaum (2014), The 29 September 1969, Ceres, South Africa, Earthquake: Full Waveform Moment Tensor Inversion for Point Source and Kinematic Source Parameters, Bull. Seis. Soc. Am., 104(1), 576-581.

Lengliné, O., and D. Marsan (2009), Inferring the coseismic and postseismic stress changes caused by the $2004 \mathrm{mw}=6$ parkfield earthquake from variations of recur- 
rence times of microearthquakes, J. Geophys. Res., 114(B10), 2156-2202, doi:10.1029/ 2008JB006118

Lengliné, O., B. Enescu, Z. Peng, and K. Shiomi (2012), Decay and expansion of the early aftershock activity following the 2011, Mw9.0 Tohoku earthquake, Geophys. Res. Lett., 39(18), 877-6, doi:10.1029/2012GL052797.

Leseane, K., E. A. Atekwana, K. L. Mickus, M. G. Abdelsalam, E. M. Shemang, and E. A. Atekwana (2015), Thermal perturbations beneath the incipient Okavango Rift Zone, northwest Botswana, J. Geophys. Res. Solid Earth, 120, 1-19.

Liu, M., and S. Stein (2016), Mid-continental earthquakes: Spatiotemporal occurrences, causes, and hazards, Earth Science Reviews, 162, 364-386.

Modisi, M. P., E. A. Atekwana, A. B. Kampunzu, and T. H. Ngwisanyi (2000), Rift kinematics during the incipient stages of continental extension: Evidence from the nascent Okavango rift basin, northwest Botswana, Geology, 28(10), 939-942.

Nguuri, T. K., J. Gore, D. E. James, S. J. Webb, C. Wright, T. G. Zengeni, O. Gwavava, and J. A. Snoke (2001), Crustal structure beneath southern Africa and its implications for the formation and evolution of the Kaapvaal and Zimbabwe cratons, Geophys. Res. Lett., 28(13), 2501-2504, doi:10.1029/2000GL012587.

Nocquet, J. M. (2012), Present-day kinematics of the Mediterranean: A comprehensive overview of GPS results, Tecton., 578, 220-242.

Nuttli, O. W. (1973), The Mississippi Valley earthquakes of 1811 and 1812: Intensities, ground motion and magnitudes, Bull. Seis. Soc. Am., 63(1), 227-248.

Nyblade, A. A., and C. A. Langston (1995), East African earthquakes below $20 \mathrm{~km}$ depth and their implications for crustal structure, Geophys. J. Int., 121, 49-62.

Okada, Y. (1985), Surface deformation due to shear and tensile faults in a half-space, Bull. Seismol. Soc. Am., 75(4), 1135-1154.

Pastier, A.-M., O. Dauteuil, M. Murray-Hudson, F. Moreau, A. Walpersdorf, and K. Makati (2017), Is the Okavango Delta the terminus of the East African Rift System? Towards a new geodynamic model: Geodetic study and geophysical review, Tecton., 712-713(C), 469-481.

Peng, Z., and P. Zhao (2009), Migration of early aftershocks following the 2004 parkfield earthquake, Nat. Geosci., 2, 877-881, doi:10.1038/ngeo697.

Prieto, G. A., M. Florez, S. A. Barrett, G. C. Beroza, P. Pedraza, J. F. Blanco, and E. Poveda (2013), Seismic evidence for thermal runaway during intermediate-depth 
earthquake rupture, Geophysical Research Letters, 40(23), 6064-6068, doi:10.1002/ 2013GL058109.

Reeves, C. V. (1972), Rifting in the Kalahari?, Nature, 237(5350), 95-96.

Reyners, M., D. Eberhart-Phillips, and G. Stuart (2007), The role of fluids in lower-crustal earthquakes near continental rifts, Nature, 446(7139), 1075-1078.

Ruiz, S., M. Metois, A. Fuenzalida, J. Ruiz, F. Leyton, R. Grandin, C. Vigny, R. Madariaga, and J. Campos (2014), Intense foreshocks and a slow slip event preceded the 2014 iquique Mw 8.1 earthquake, Science, 345(6201), 1165-1169, doi: $10.1126 /$ science. 1256074 .

Russel, J. K., and M. G. Kopylova (1999), A steady state conductive geotherm for the north central Slave, Canada: Inversion of petrological data from the Jericho Kimberlite pipe, J. Geophys. Res., 104(B4), 7089-7101.

Russell, J. K., L. A. Porritt, Y. Lavallée, and D. B. Dingwell (2012), Kimberlite ascent by assimilation-fuelled buoyancy, Nature, 481(7381), 352-356.

Rutter, E. H., and K. H. Brodie (2004), Experimental intracrystalline plastic flow in hotpressed synthetic quartzite prepared from Brazilian quartz crystals, J. Struct. Geol, 26(2), 259-270.

Saria, E., E. Calais, D. S. Stamps, D. Delvaux, and C. Hartnady (2014), Present-day kinematics of the East African Rift, J. Geophys. Res Solid Earth, 119(4), 3584-3600.

Schmitz, M. D., and S. A. Bowring (2003), Ultrahigh-temperature metamorphism in the lower crust during Neoarchean Ventersdorp rifting and magmatism, Kaapvaal Craton, southern Africa, GSA Bull., 115(5), 533-548.

Scholz, C. H., T. A. Koczynski, and D. G. Hutchins (1976), Evidence for incipient rifting in southern africa, Geophysical Journal of the Royal Astronomical Society, 44(1), 135144, doi:10.1111/j.1365-246X.1976.tb00278.x.

Shelly, D., G. Beroza, and S. Ide (2007), Non-volcanic tremor and low-frequency earthquake swarms, Nature, 446, 305-307, doi:10.1038/nature05666.

Shudofsky, G. N., S. Cloetingh, S. Stein, and R. Wortel (1987), Unusually deep earthquakes in East Africa: Constraints on the thermo-mechanical structure of a continental rift system, Geophys. Res. Lett., 14(7), 741-744.

Sibson, R. H. (1989), High-angle reverse faulting in northern New Brunswick, Canada, and its implications for fluid pressure levels, J. Struct. Geol, 11(7), 873-877. 
Simons, M., Y. Fialko, and L. Rivera (2002), Coseismic deformation from the 1999 mw 7.1 hector mine, california, earthquake as inferred from insar and gps observations, Bull. Seis. Soc. Am., 92(4), 1390-1402, doi:10.1785/0120000933.

Stamps, D. S., L. M. Flesch, and E. Calais (2014), Current kinematics and dynamics of Africa and the East African Rift System, J. Geophys. Res., 119(6), 5161-5186, doi:10. 1002/2013JB010717.

Tedla, G. E., M. v. d. Meijde, A. A. Nyblade, and F. D. v. d. Meer (2011), A crustal thickness map of Africa derived from a global gravity field model using Euler deconvolution, Geophys. J. Int, 187(1), 1-9, doi:10.1111/j.1365-246X.2011.05140.x.

Townend, J., and M. D. Zoback (2000), How faulting keeps the crust strong, Geology, 28(5), 399-402.

Tregoning, P., R. Burgette, S. C. McClusky, S. Lejeune, C. S. Watson, and H. McQueen (2013), A decade of horizontal deformation from great earthquakes, J. Geophys. Res Solid Earth, 118(5), 2371-2381.

Wehrens, P., A. Berger, M. Peters, T. Spillmann, and M. Herwegh (2016), Deformation at the frictional-viscous transition: Evidence for cycles of fluid-assisted embrittlement and ductile deformation in the granitoid crust, Tecton., 693(Part A), 66-84.

Weise, S. M., K. Bräuer, H. Kämpf, G. Strauch, and U. Koch (2001), Transport of mantle volatiles through the crust traced by seismically released fluids: a natural experiment in the earthquake swarm area Vogtland/NW Bohemia, Central Europe, Tecton., 336(1-4), 137-150, doi:10.1016/S0040-1951(01)00098-1.

Xu, W., R. Dutta, and S. Jónsson (2015), Identifying active faults by improving earthquake locations with insar data and bayesian estimation: The 2004 Tabuk (Saudi Arabia) earthquake sequence, Bull. Seis. Soc. Am., 105(2A), 765-775, doi:10.1785/0120140289.

Youssof, M., H. Thybo, I. M. Artemieva, and A. Levander (2013), Moho depth and crustal composition in Southern Africa, Tecton., 609(C), 267-287. 
Table 1. Catalog of the newly detected events. The time of occurrence corresponds to the time at which coherency between the template and the continuous signal is the highest. The locations of the detected events are the same as the location of the template they matched, as indicated in the ISC catalog. Magnitudes are estimated by calculating the amplitude ratio (see Supp. Mat.).

\begin{tabular}{ccccccccc}
\hline Year & Month & Day & Hour & Minute & Second & Latitude & Longitude & Magnitude \\
\hline 2016 & 12 & 11 & 17 & 9 & 32.05 & -22.5367 & 24.9746 & 3.3 \\
2016 & 12 & 11 & 19 & 28 & 14.05 & -22.6610 & 25.0010 & 3.5 \\
2016 & 12 & 13 & 21 & 46 & 46.05 & -22.5367 & 24.9746 & 3.3 \\
2016 & 12 & 14 & 17 & 22 & 52.05 & -22.6610 & 25.0010 & 3.6 \\
2016 & 12 & 27 & 12 & 1 & 44.05 & -22.6913 & 25.1021 & 3.6 \\
2016 & 12 & 27 & 16 & 16 & 18.05 & -22.6610 & 25.0010 & 3.8 \\
2016 & 12 & 28 & 10 & 56 & 54.05 & -22.9860 & 25.1260 & 3.7 \\
2016 & 12 & 28 & 15 & 12 & 22.05 & -22.6610 & 25.0010 & 3.4 \\
2016 & 12 & 29 & 7 & 39 & 24.05 & -22.9870 & 24.9980 & 3.7 \\
2017 & 03 & 14 & 18 & 38 & 20.05 & -22.5646 & 25.0868 & 3.1 \\
2017 & 03 & 15 & 15 & 12 & 2.050 & -22.6610 & 25.0010 & 3.9 \\
2017 & 03 & 23 & 17 & 43 & 12.05 & -22.5367 & 24.9746 & 3.5 \\
2017 & 03 & 27 & 10 & 18 & 4.050 & -22.6610 & 25.0010 & 3.9 \\
2017 & 04 & 02 & 8 & 30 & 40.05 & -22.5367 & 24.9746 & 3.5 \\
2017 & 04 & 05 & 12 & 29 & 10.05 & -22.3206 & 25.4211 & 3.4 \\
2017 & 04 & 11 & 11 & 57 & 32.05 & -22.5367 & 24.9746 & 3.5 \\
2017 & 04 & 12 & 19 & 3 & 28.05 & -22.8180 & 24.9340 & 3.8 \\
2017 & 04 & 21 & 11 & 52 & 4.050 & -22.5367 & 24.9746 & 3.5 \\
2017 & 04 & 21 & 21 & 36 & 48.05 & -22.6610 & 25.0010 & 3.6 \\
2017 & 04 & 27 & 5 & 36 & 56.05 & -22.6784 & 25.1558 & 3.3 \\
\hline
\end{tabular}




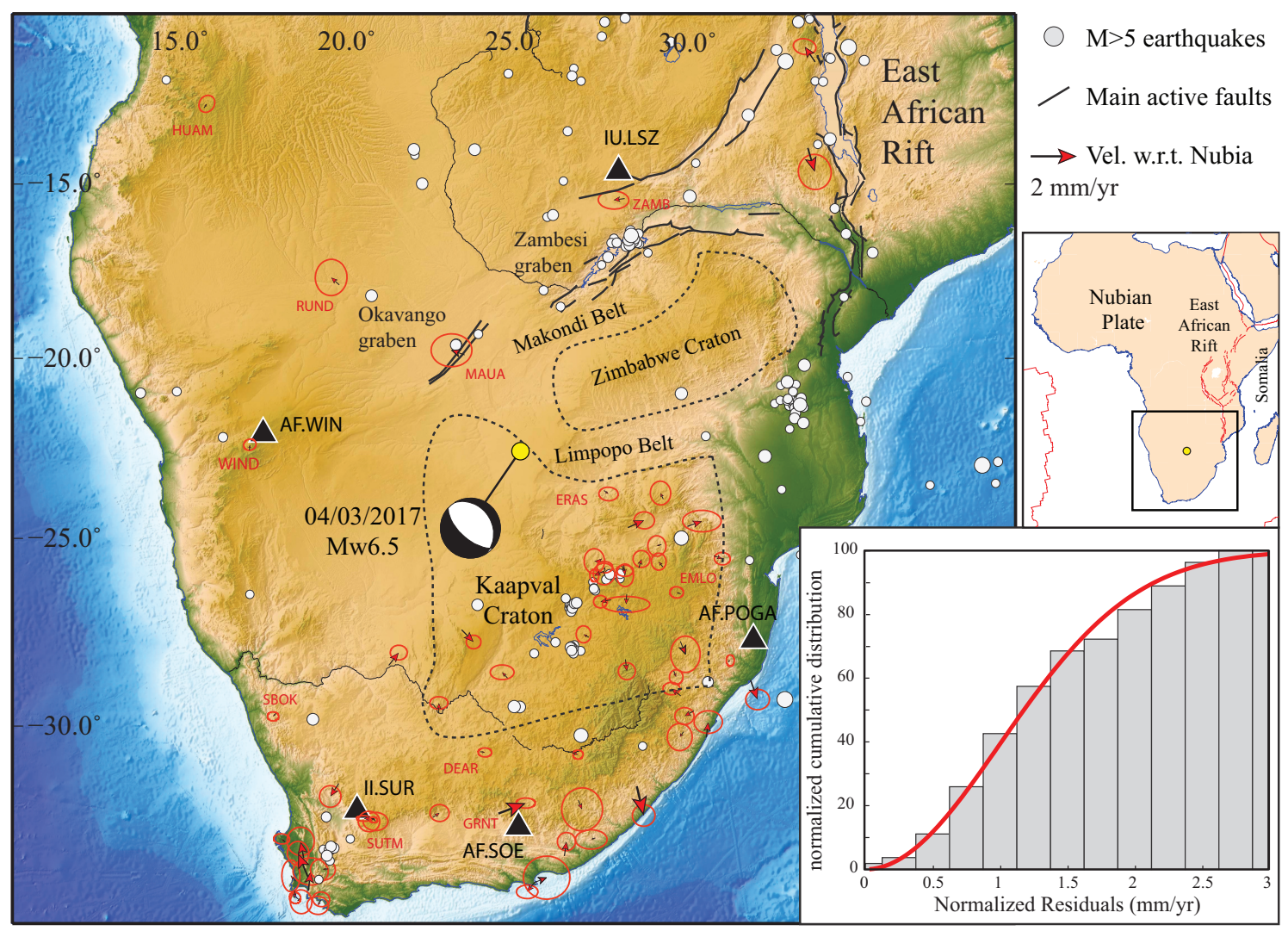

Figure 1. Regional context - Map of the southern tip of the African continent. The NEIC epicenter of the April 3, 2017, Bostwana earthquake is shown with a yellow circle, with its GCMT focal mechanism. Black triangles indicate the location of seismological stations used for template matching. Grey dots are earthquake epicenters from the NEIC catalog covering the 1974-2018 time interval. Dotted lines show the boundaries of the Kaapval and Zimbabwe archean cratons. Solid black lines show major faults associated with recent topographic features. Red arrows show residual GPS velocities with respect a rigid plate assumption with their $95 \%$ confidence ellipse. Uncertainties include site-dependent, time-correlated colored noise. Red labels indicate the code name of some of the GPS stations. Lower right inset shows the normalized cumulative distribution of GPS velocity residuals (both north and east components). The red line shows the theoretical $\chi^{2}$ distribution expected if residuals are normally distributed in two dimensions with a unit variance. 


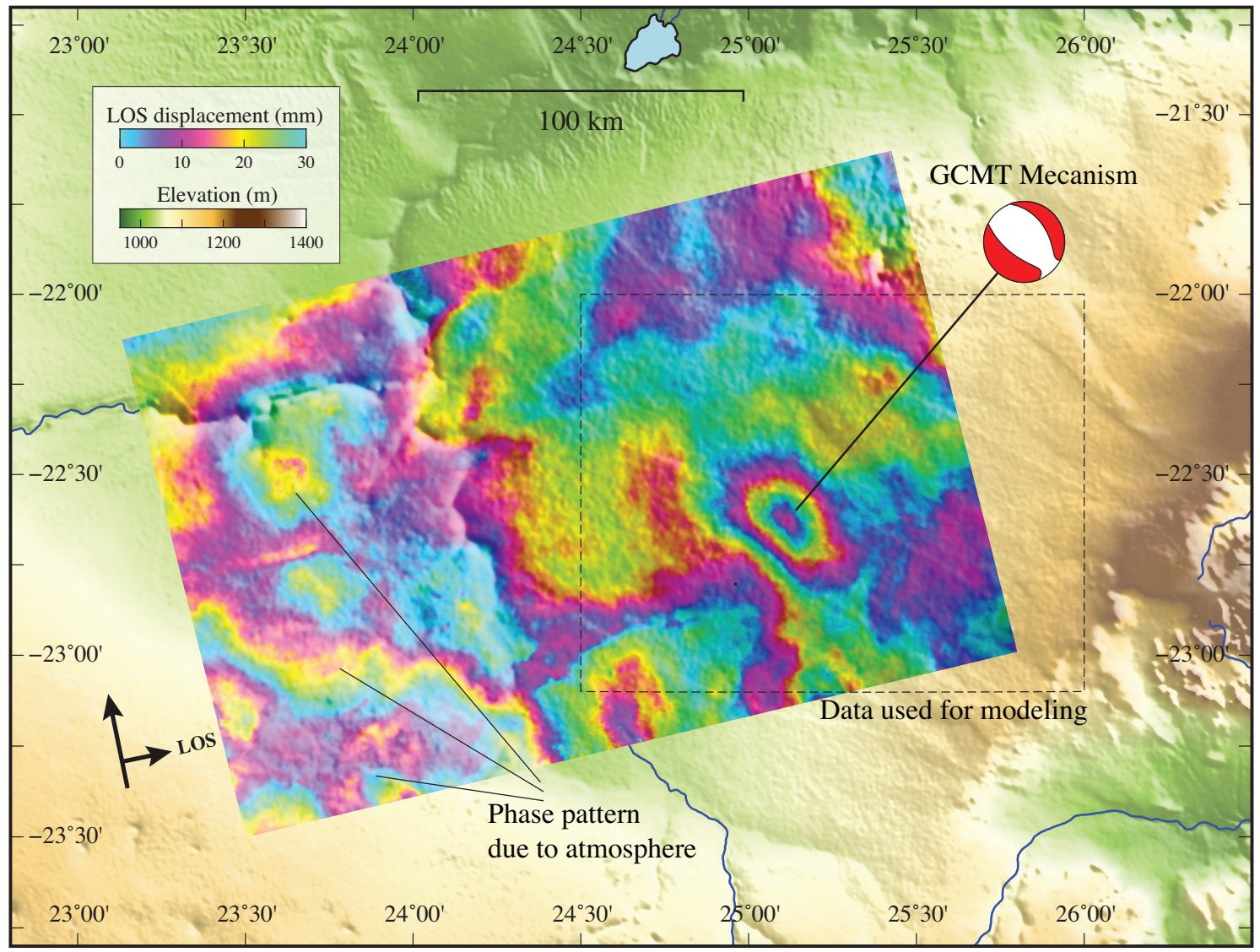

Figure 2. InSAR data - Interferogram derived from Sentinel 1 acquisitions on March 30th and April 11th, 2017. One color fringe indicates $3 \mathrm{~cm}$ of displacement in the satellite Line-Of-Sight (thick black arrow). Dotted line rectangle indicates the subset of data used for the Bayesian modeling. Focal mechanism is from GCMT [Ekström et al., 2012]. Background color is the digital elevation model from SRTM [Farr and Kobrick, 2000]. Blue lines indicate major rivers. 


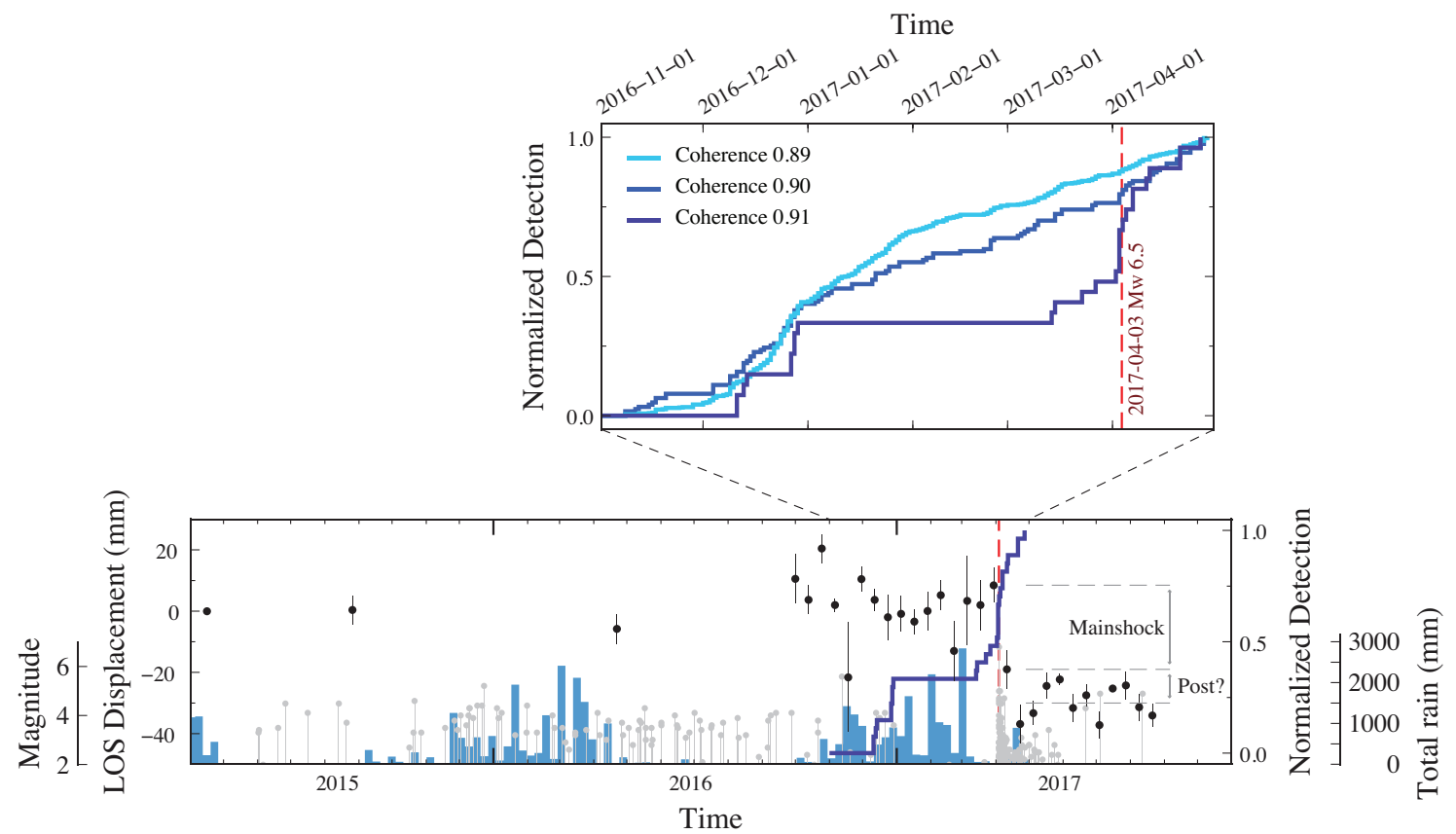

Figure 3. Template matching detection and InSAR time series - Top Normalized number of template detections as a function of time from November 2016 to late April 2017 for three coherence thresholds. The red dotted line indicates the time of the Botswana $\mathrm{M}_{\mathrm{W}} 6.5$ earthquake. Bottom Black dots are the differential displacement at the time of Sentinel 1 acquisitions between the epicentral region (average of pixels located less than $10 \mathrm{~km}$ away from the maximum displacement) and a stable region (average of pixels located between 50 and $100 \mathrm{~km}$ away from the maximum displacement). Blue line is the normalized number of template detections for a coherence threshold of 0.91. Light blue bars are the cumulative rain fall summed over weekly periods. No obvious relationship can be found between hydrological loads besides the fact that the earthquake occurred at the end of the rainfall period. Gray lines and dots are earthquake occurrences and their magnitude from the ISC catalog. Rainfall and earthquakes are considered between $19^{\circ}$ and $30^{\circ}$ of longitude and $27^{\circ}$ and $17^{\circ}$ of latitude south. 


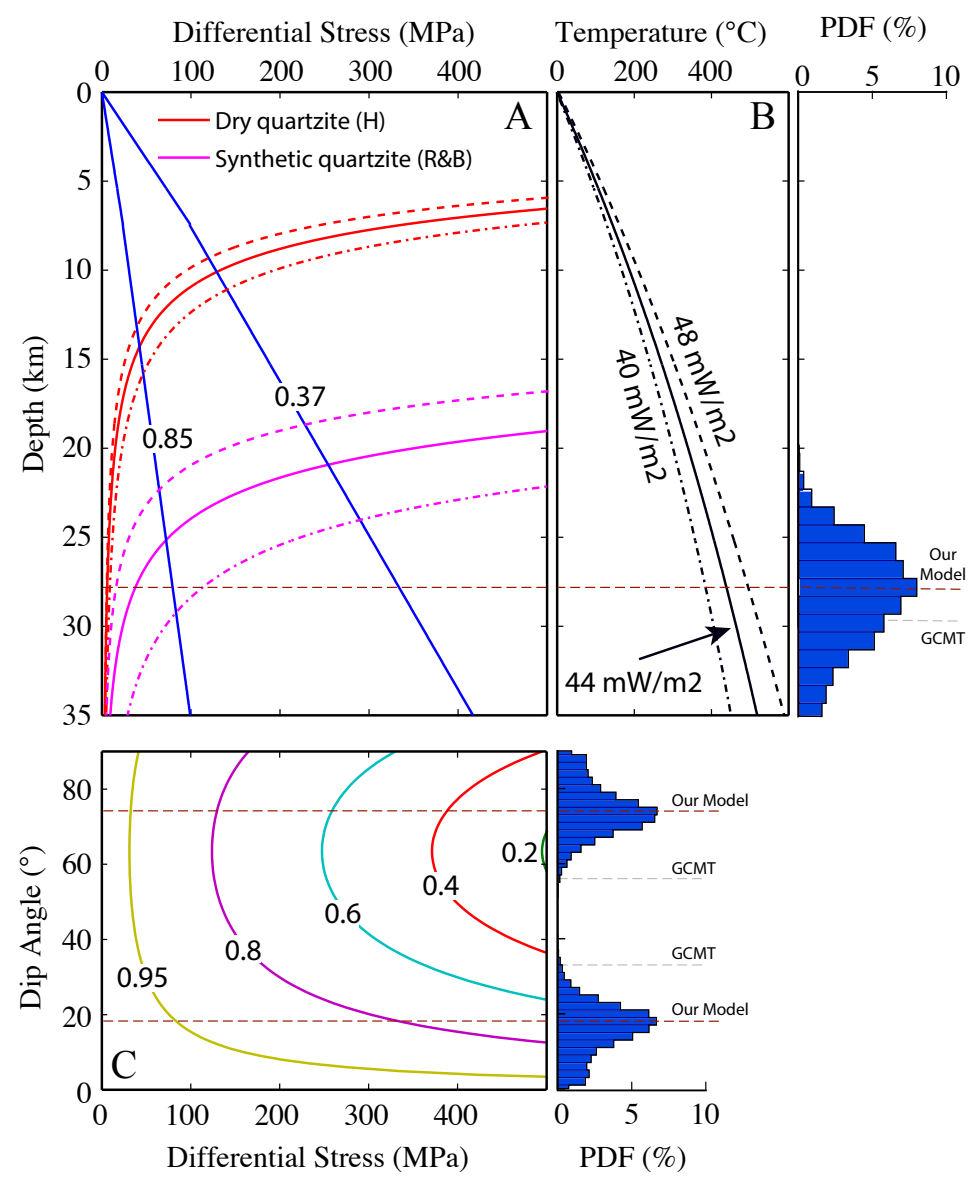

Figure 4. Mechanical behavior of rocks and earthquake source parameters - A Red and magenta lines show dislocation creep flow laws using dry and synthetic quartzite rheologies for three geotherms shown on panel B. Flow law parameters for wet quartzite are from Rutter and Brodie [2004] and for dry quartzite from [Hirth et al., 2001]. Strain rate is $10 \times 10^{-18} \mathrm{~s}-1$. We use a surface heat flow of $44 \mathrm{~mW} / \mathrm{m}^{2}$, the average of four close-by measurements [Ballard et al., 1987], and computed the corresponding crustal geotherm [Russel and Kopylova, 1999]. Blue lines show friction law for hydrostatic $\left(\lambda_{V}=0.37\right)$ and sub-lithostatic $\left(\lambda_{V}=0.85\right)$ pore fluid pressure [Byerlee, 1978]. B Geotherms derived from a surface heat flow of $44 \pm 10 \% \mathrm{~mW} / \mathrm{m}^{2}$ calculated following [Russel and Kopylova, 1999]. C Differential stress $\left(\sigma_{1}-\sigma_{3}\right)$ required for frictional reactivation of cohesionless normal faults at $30 \mathrm{~km}$ depth as a function of their dip angle for different values of the pore fluid factor $\lambda_{V}$, following [Sibson, 1989]. Lithostatic conditions correspond to $\lambda_{V}=1$. Histograms are the probability density functions of the earthquake source parameters estimated from InSAR data, including centroid depth and dip angle. 
Figure 1. 


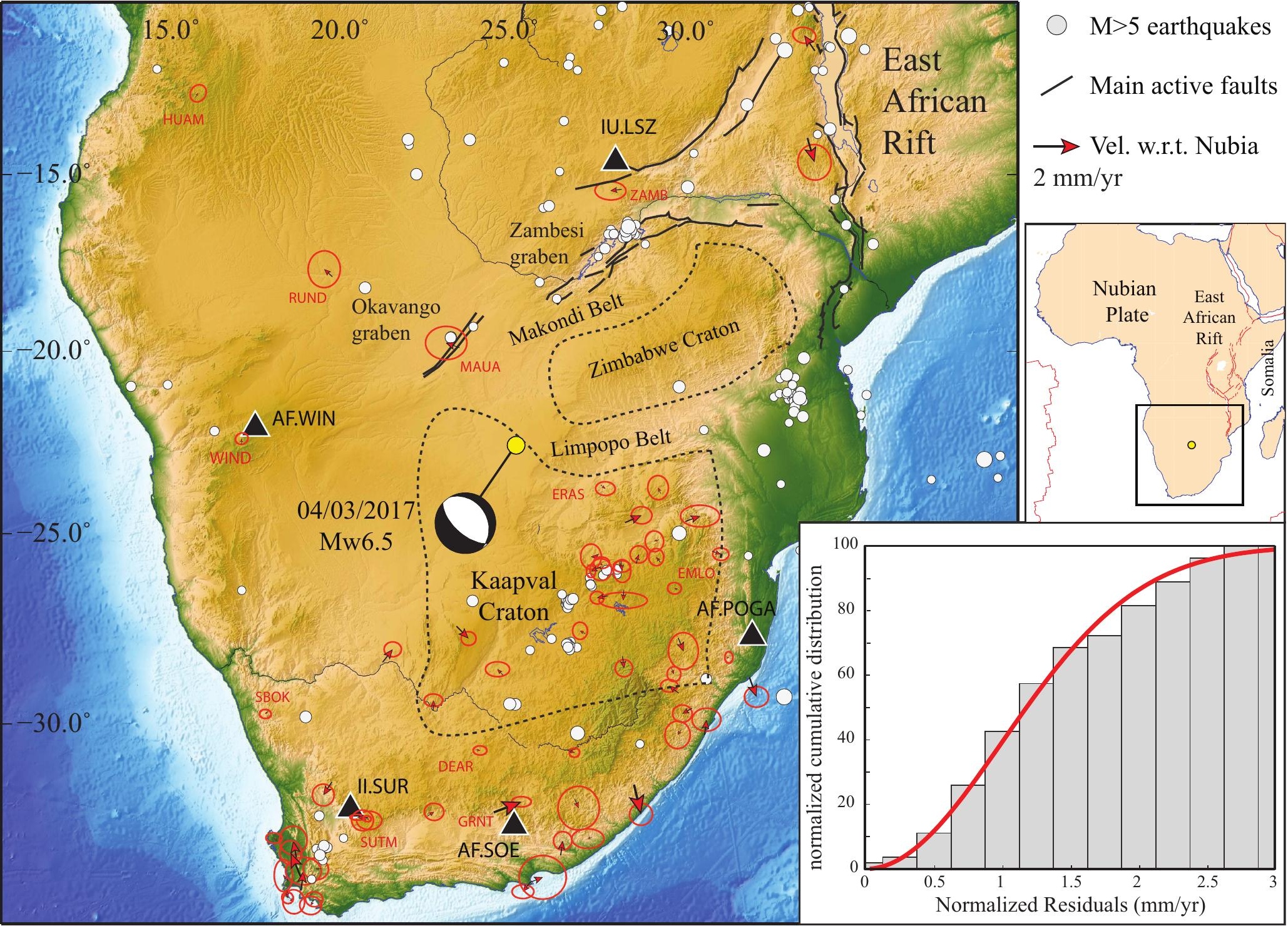


Figure 2. 


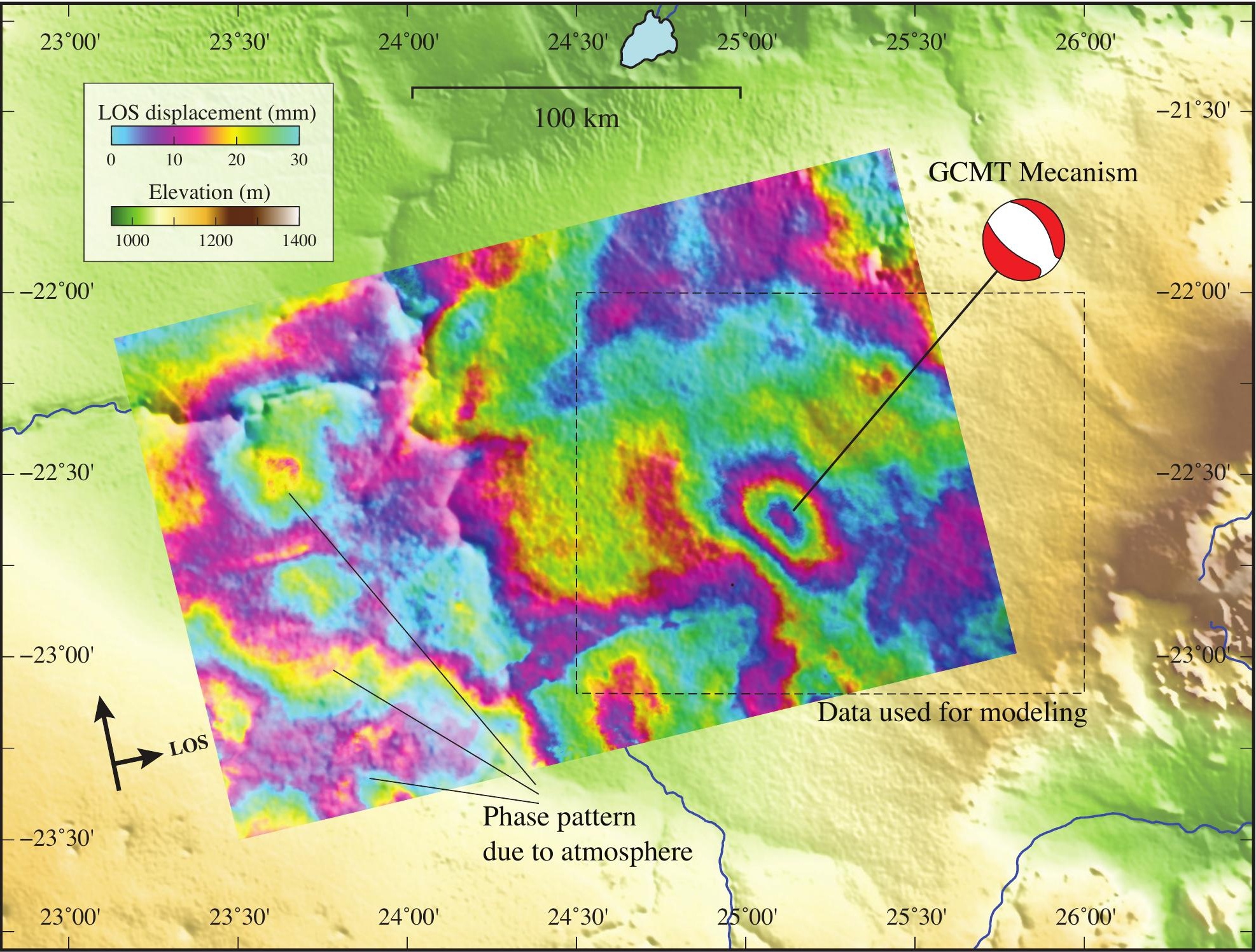


Figure 3. 

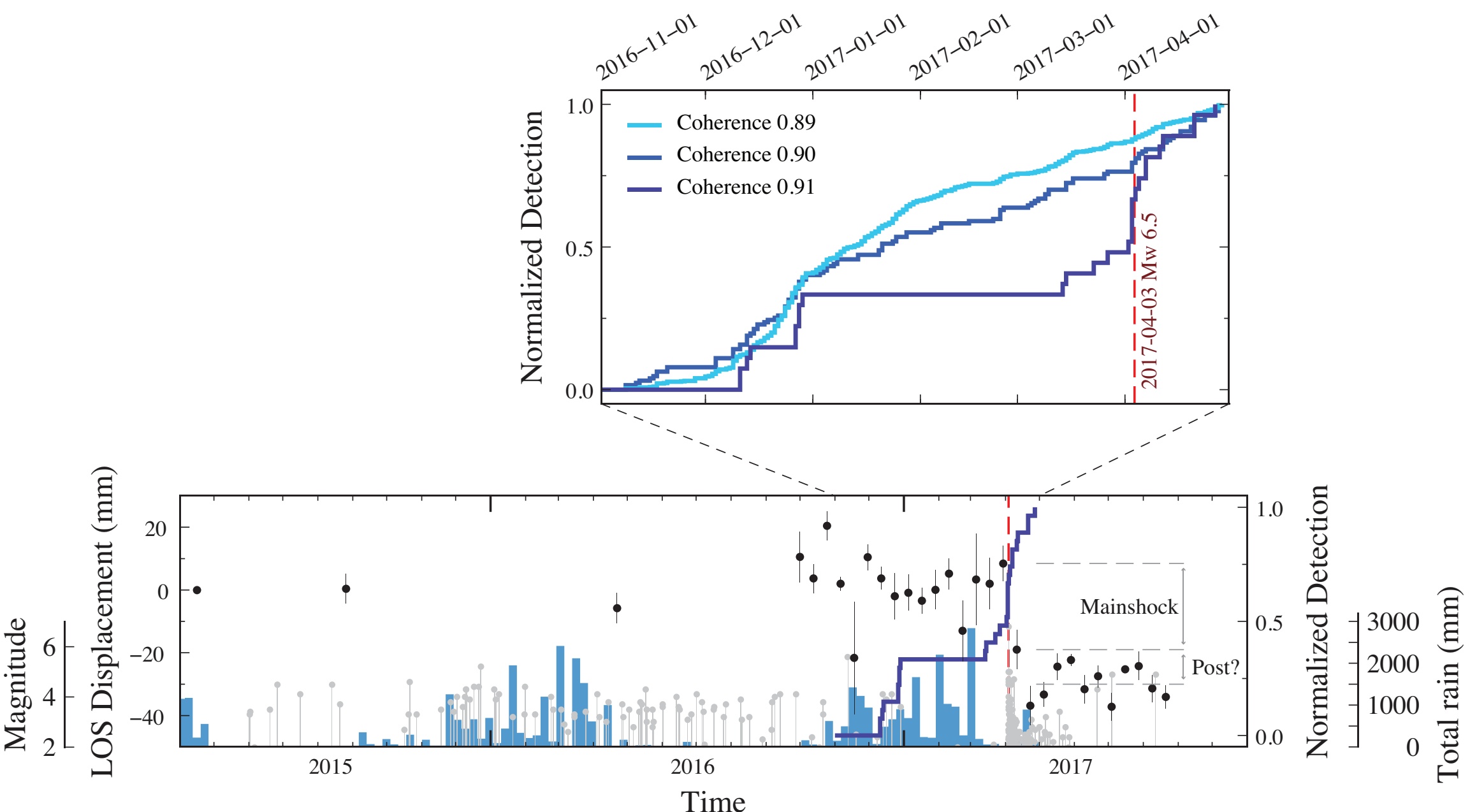

Time 
Figure 4. 
Differential Stress (MPa) $\quad$ Temperature $\left({ }^{\circ} \mathrm{C}\right) \quad$ PDF $(\%)$

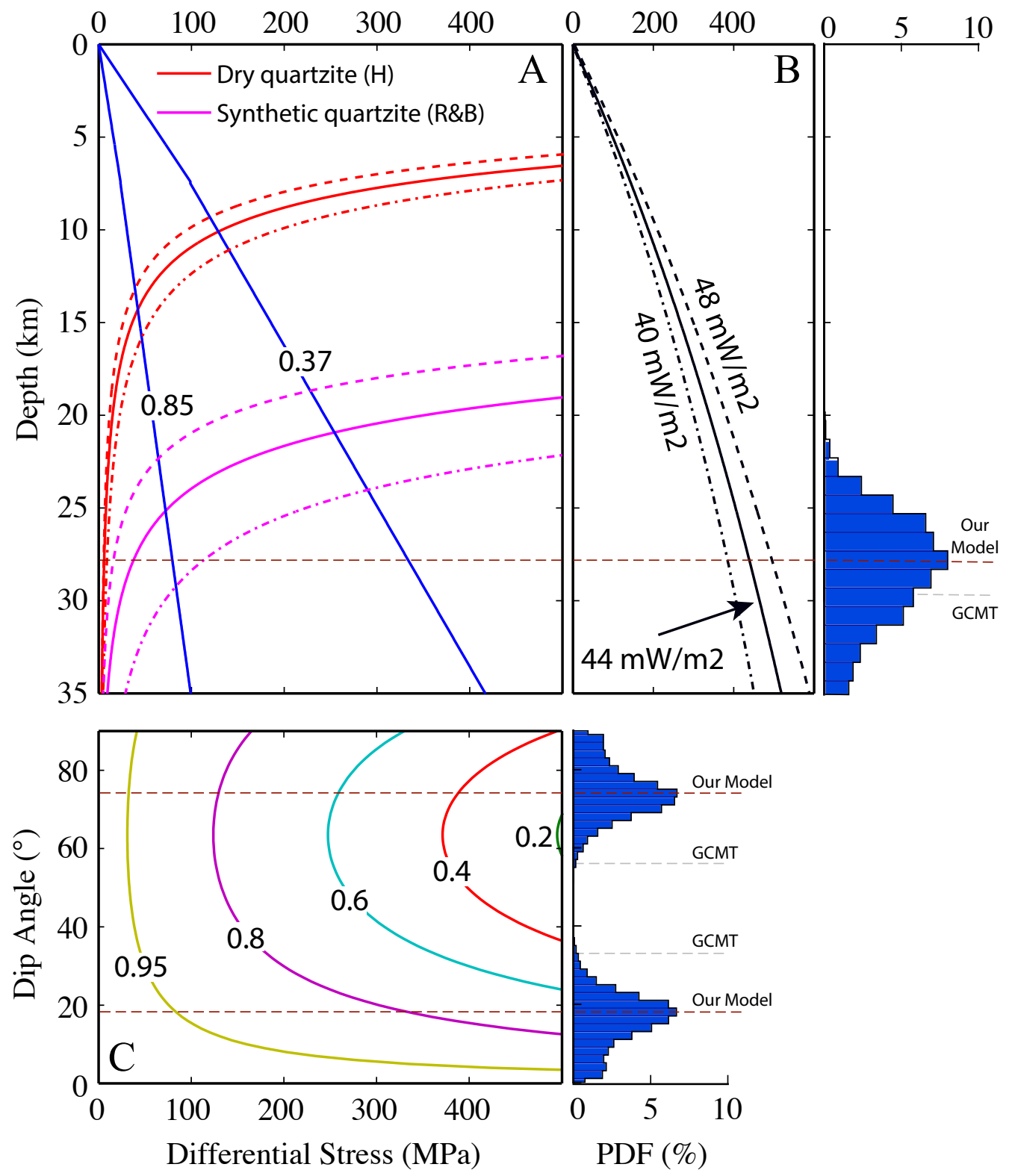

